Est Ag 43 (2008) 365-387

\title{
Creación y Misión
}

Al ver tu cielo, hechura de tus dedos, la luna y las estrellas que fijaste tú, ¿qué es el hombre para que de él te acuerdes, el hijo de Adán para que de él te cuides? Apenas inferior a un dios le hiciste, coronándole de gloria y de esplendor; le hiciste señor de las obras de tus manos, todo fue puesto por ti bajo sus pies (Sal 8, 4-7).

\section{INTRODUCCIÓN}

Hace algunos años me hicieron una complicada intervención quirúrgica. No lo olvidaré: un equipo de médicos y auxiliares me rodeaban en el quirófano saturado de luz. Trepanaron mi casco cerebral, fueron levantando cada una de las capas que cubren la masa encefálica: piamadre, duramadre y aracnoides, y se sumergieron en el misterio de millones y millones de neuronas que conforman el cerebro. Colaboré en la operación, señalando imágenes oralmente, puesto que se hacía sin anestesia. El tumor estaba en la zona del habla materna. Cuando el logopeda estimulaba determinadas zonas de la periferia de ese punto, me salían las voces de otros idiomas aprendidos. Para mí un misterio deslumbrante: en un minúsculo punto del lóbulo frontal izquierdo estaba grabada una estructura, y en su entorno, el resto de mis aprendizajes lingüísticos.

Aquella mañana, sobre el lecho quirúrgico del Hospital de la Universidad de Seattle, comencé a reconciliarme con la materia. Moléculas, átomos y millones y millones de interconexiones en red que la forman. De repente comprendí que el cerebro humano es extraordinariamente complejo. Contiene alrededor de mil millones de células nerviosas (neuronas) interconectadas en una vasta red a través de un billón de conexiones (sinapsis) y que puede ser subdividida en subsecciones o subredes que se comunican entre sí en forma de red.

Me surgió con particular intensidad la pregunta: ¿Qué es la vida? Los creyentes en el Dios de la Vida, en el infinito poder de su Creación, no podemos parapetarnos en abstracciones y generalidades, y dejar de escudriñar lo más en profundo que hay en ella, hasta en sus niveles mínimos 
de la biología molecular, que, ya entrado el siglo XXI, ha comenzado a anunciar nuevos paradigmas. Me llegué a convencer de que hay que aproximarse más y más al misterio de la vida en su constitución físico-química antes de apresurarnos a definir una ética y una conducta coherente con ella. Hay que acompañar desde el interior de la ciencia los procesos de cambio que se han producido en la evolución del mundo desde la materia primera (Duve: 1999; Soberón:12).

Meses más tarde, topé con El error de Descartes, una obra escrita por Antonio Damasio, prestigioso neurólogo americano, que demostraba fehacientemente que las emociones no eran asunto del espíritu sino que estaban localizadas en distintas zonas del cerebro y que el pensamiento lineal, lógico y matemático del autor de La duda metódica había sido superado por los avances científicos nucleares que aportaban nuevas comprensiones de las redes biológicas y genéticas entre las células y sus componentes. La claridad y evidencia de este pensamiento hacían poner en duda mi comprensión tradicional de las formas de inserción del alma espiritual en los tejidos de la carne de mi cuerpo. Aprendí con Teilhard de Chardin, que estaba formado de una materia que entretejía mi corazón, su sensibilidad, su energía: que todo en mí procedía del Dios Viviente y Creador; que era el resultado de la evolución de aquella primera masa informe que se expresaba en el hombre como inteligencia cósmica.

Luego me llegó el complemento bíblico. "En el principio Dios creó la Esencia Viviente" (Gen 1,1). A partir de la versión griega de Los Setenta, existe una corriente bíblica que traduce así el primer versículo de los libros sagrados. Calza bien a este propósito: Dios creó primero la Esencia Viviente y, después, el Cielo y la Tierra. Y no importa que científicamente se adecue o no a lo real. La Vida es la energía transformadora que a lo largo de los seis días de la Creación va desencadenando un proceso hacia la maduración de la conciencia cósmica que vuelve a su punto original, el Creador. La materia deja de ser algo inerte inanimado, vacío; está llena de Vida desde el estallido del primer Big-Ban, en una complejidad desbordante y creciente en progresión geométrica.

Gravitons, topquarks, quarks, electrones y átomos van enriqueciendo un trenzado de relaciones y sensibilidades cuya culminación última es la conciencia humana, que comenzó a surgir desde la explosión primera a partir de los elementos básicos que conformaban la materia original. Todo esto me ha llevado a repensar el sentido de la vida misionera y buscar una camino frente a la crisis que se ha establecido en la posmodernidad en 
torno al sentido de la fe en el más allá y la ciencia en que se va revelando la fuerza omnipotente y creadora de Dios.

\section{UN NUEVO PARADIGMA}

Nadie duda que la sociedad está en crisis. Occidente en su racionalidad lineal se ha desbordado a sí mismo. Los grandes ídolos de la ciencia, la tecnología y la industrialización se han hecho dueños y señores del mundo. En política, dos grandes revoluciones, China y Rusia; la guerra fría, el fascismo, el comunismo, el capitalismo, los desastres ecológicos cósmicos, la grieta cada vez más ancha entre ricos y pobres a pesar del ideal quimérico del progreso, el fantasma del terrorismo a costa del cual se acorrala y acongoja a la humanidad. Todo ello en medio de las grandes conquistas democráticas de la Revolución Francesa como expresión más lograda de los pueblos occidentales (GS, 4; Bosch:445; Kuschel: 235).

Estos males que afectan a la sociedad global, en índice superior han afectado a la Iglesia y al cristianismo. El Concilio Vaticano II ha abierto las ventanas para que entre oxígeno y se ha franqueado ante el mundo y la sociedad (GS 1-3). Pero da la sensación de que ha llegado demasiado tarde. Por una parte reconoce que formamos parte de la condición humana, pero sigue perdiendo posiciones, y, como reconoce Bosch, "ser cristiano hoy es más impedimento que ventaja" (Bosch: 446). Las grandes religiones del mundo han vuelto a tomar impulso misionero más que el cristianismo a lo largo de su historia.

Por otra parte, al debilitarse el sentido de la misión, después del Concilio muchos religiosos y sacerdotes católicos han abandonado la vida eclesial, las vocaciones se han extinguido, han aumentado los promedios de edad de los clérigos y las sociedades del viejo mundo tienen sus iglesias vacías o llenas de gente adulta.

La Iglesia es eminentemente misionera sin duda (Mc 28, 19-20; LG, 1 ss; AG, 1ss). Pero, ¿cómo compatibilizar este mandato de Jesús con esta crítica realidad? El asunto está en descubrir nuevas modalidades y estructuras de ser y ejercer el anuncio hoy y saber relacionarse con el mundo al que nos debemos, abrirnos y escucharlo. Esta relación exige una actitud radicalmente distinta, que nos abra creativamente de lo viejo a lo nuevo. Quitar el colonialismo de la cultura occidental que acompañaba el aliento misionero y convertirnos al Dios de la Vida y sentir con Él allí donde se manifieste. Decía Juan XXIII poco antes de morir: No es que el evangelio haya cambiado, es que hemos comenzado a comprenderlo mejor. 


\section{2. ¿FIELES O INFIELES?}

Surgen algunas preguntas imposibles de eludir. La primera es si una nueva mirada a la crisis no significará otra cosa que tratar de recuperar la abundancia de fieles perdidos o si, más bien, algunos pretenden buscar superar la crisis de modo creativo en función de la construcción del Reino. De hecho la respuesta a esta pregunta han sido una serie de fundamentalismos proselitistas que enarbolan la propuesta tradicional: "Extra Ecclesiam nulla salus". En esa corriente estarían las sectas cristianas o seudocristianas y determinados sectores de la Iglesia católica a quienes abrasa el celo y la ansiedad por hacer que todos se conviertan a su modo de entender a Cristo.

Jacques Dupuis, después de recoger la opinión negativa de Barth sobre las alteridades religiosas, presenta en panorámica una actitud mucho más positiva de otros autores sobre la relación entre otras religiones y el cristianismo. Se plantea si estas religiones no eran ya una praeparatio evangelica. Dicho de otro modo: las demás religiones tienen con el cristianismo una relación de religión de lo natural con respecto a lo sobrenatural, entendiendo que la gracia perfecciona a la naturaleza (Dupuis: 191). ¿Qué papel desempeñan las demás religiones dentro del misterio de la salvación de Jesucristo? Es evidente, según los estudios realizados durante los últimos años, que las grandes religiones no cristianas (hinduismo, budismo, Islam, por ejemplo) mantienen en su discurso profundo una tentativa de respuesta a los grandes problemas de la humanidad, como el absoluto, la dignidad de la persona humana, la mística, el medio ambiente, etc. "De esta forma pasaron a primer plano sistemas enteros de pensamiento, cada uno de los cuales constituía una cosmovisión específica, irreductible a las otras. Tampoco las distintas tradiciones religiosas eran meras portadoras de sistemas religiosos; cada una de ellas tenía una dimensión mística; cada una poseía sus videntes y sus profetas, sus tantos y sus figuras salvíficas, sus ascetas y sus místicos" (Dupuis: 192). Esto hacía que hubiera dos posiciones encontradas: por una parte los que consideraban que todas las religiones representaban un deseo innato de relacionarse con lo divino, pero Jesucristo es el único Señor y representa la respuesta universal de Dios a esta aspiración, es la única religión sobrenatural; por otra, las diversas religiones representan en sí intervenciones específicas de Dios en la historia de salvación, lo cual implica que ninguna religión es puramente natural, es una intervención histórica y mediación existencial de Dios en la historia de los pueblos (Ib.:194). La primera llamada "del cumplimiento" ha sido defendida durante la primera mitad del siglo 
$\mathrm{XX}$ por teólogos que tuvieron mucha influencia en su tiempo, como Jean Daniélou, con su teoría de la religión cósmica y la revelación cristiana; Henri de Lubac con su doctrina sobre el cristianismo como eje del plan de Dios; Hans Urs von Baltasar sobre Cristo como "el universal concreto". Existe por el contrario una posición que se vincula más a las tradiciones religiosas y no establece diferencia entre lo humano y lo divino, por la presencia de Dios al interior de sus culturas y su historia, y de ninguna manera acentúan las diferencias sino que se abren desde sus raíces al hecho creador. Entre ellos se cuentan Karl Rahner con su teoría sobre los cristianos anónimos; Raimon Panikkar sobre el Cristo desconocido; Hans Küng sobre los caminos de salvación; Gustave Thils sobre las mediaciones de la salvación.

Las tres teorías que encuadran las tres visiones diferentes serían el eclesiocentrismo, el cristocentrismo y el teocentrismo, conforme a los distintos ejes articuladores de cada una de ellas. El paso del eclesiocentrismo al cristocentrismo supondría que la salvación solamente se produciría a través de la confesión explícita de la fe en Jesucristo en la comunidad de los creyentes. El segundo, del cristocentrismo al teocentrismo, tampoco satisface ya que en su lugar habría que colocar una visión teocéntrica, donde la referencia a Jesucristo sería meramente aleatoria y ocasional dado que el mundo ha sido creado para todos los hijos de la tierra. En el tránsito del eclesiocentrismo al cristocentrimo, se busca fundamentar la Iglesia sobre lo que es más importante que ella, Cristo, la Palabra del Padre. Ella es un misterio derivado.(Bosch: 273 ss). Y en el orden teológico se sigue la misma orientación y no pueden estar al mismo nivel. Sólo Jesucristo es mediador del Padre creador( $(1 \mathrm{Tm} 2,5 ; \mathrm{Hb} 8,6 ; 9,15 ; 12,24)$ (Dupuis: 273).

En la teología de las religiones los autores defienden un tránsito más radical hacia lo que llaman el pluralismo. Para ellos hay que hacer una ruptura con el eje de Jesucristo en el orden de la salvación en términos normativos y no constitutivos, al modo como lo entendió Teilhard de Chardín (Chardin: 121 ss). En este caso la Salvación comienza ya con el hecho creador y no hay posibilidad de tener una adecuada comprensión de éste sin mirar al primero (Jn 1,1 ss). La revolución consiste en reconocer para todas las religiones el mismo valor horizontal, y renunciar a toda pretensión de exclusividad y normatividad para el cristianismo o para Jesucristo (Swidler: 224-230).

Esta posición sería avanzar la doctrina del Concilio Vaticano II, que mantiene una posición ambigua en torno a este tema (GS 1,2,3, ss). La fe 
en Jesucristo afirmaría su identidad en la mirada que se establece sobre el resto de las realidades del mundo, pero abierta y sin ninguna arrogancia frente a lo que defienden cada una de las distintas religiones. La verdad jamás puede ser única y definida en verdades exclusivas, sino múltiple, compleja, policromática.

El magisterio posconciliar plantea algunas variantes. Paulo VI en su encíclica Ecclesiam Suam (agosto de 1964) habla de un diálogo de la Iglesia con el mundo, con otras religiones, con los cristianos, consigo misma. A pesar de que afirma que la única religión verdadera es la Católica, acepta "los valores espirituales y morales de las varias confesiones religiosas no cristianas" (AAS 56 (1964), pp. 654-655). Juan Pablo II en la declaración Nostra Aetate pone en el medio el común origen de Dios y el destino definitivo conforme al mismo plan de Dios. En su encíclica Redemptor Hominis (marzo del 79) Juan Pablo II hace intervenir al Espíritu de Dios más allá del universo cristiano, que está presente y operante en el mundo, en las tradiciones religiosas en la unidad entre sus miembros.

Sigue apareciendo la misma perspectiva en Dominum et Vivificantem (mayo de 1996), Redemptoris Missio (diciembre de 1990). A partir de la Tertio Millennio Adveniente (noviembre de 1994) vuelve a la teoría del cumplimiento de la promesa en Xto. Sucesivos documentos de la Iglesia han mostrado una actitud vacilante en torno a este tema, que hasta ahora no ha sido abordado más que por el Concilio Vaticano II. Precisamente a partir de aquí pretendo diseñar una doctrina de la Creación en una nueva perspectiva misionera.

\section{CREADOR, MUNDO Y CIENCIA}

González Faus en su obra Autoridad de la Verdad nos trae una serie de casos donde la Iglesia ha definido como dogmáticos asuntos que pertenecían al ámbito de la ciencia. De este modo perdió el tren de la historia al devenir el Renacimiento y fue deslizándose por errores de los cuales el Papa Juan Pablo II ha tenido el coraje de pedir perdón al mundo en los últimos años. Por eso actualmente, ya no son la filosofía ni la teología las disciplinas que determinan el rumbo de la historia: son las ciencias biofisicas las que orientan el pensamiento de nuestro tiempo.

Entiendo que la ciencia, por más ambigua y frágil que sea, como cualquier realización del hombre, nos acerca al descubrimiento del poder creador de Dios, para quienes creemos en $\mathrm{El}$ : La verdad les hará libres (Jn 8, 32). Estar con la marcha de la Vida, acompañar los procesos del mundo, significa, sin duda, aproximarse al Creador, que, visto en su esencia trini- 
taria y en la acción salvífica de Jesús, significa un enriquecimiento del pensamiento y de la causa de la armonía y de la paz, en que se comprometió Francisco de Asís.

Me pregunto a este propósito qué sucederá cuando se vayan cayendo los viejos fundamentos de nuestras creencias: alma y cuerpo, cielo y tierra, dónde van nuestras cenizas, si habrá o no otros mundos como el nuestro, cuál es el alma de los animales, qué sucederá si se logra clonar el ser humano, cuáles serán las condiciones de la bioética para el siglo XXI, dónde nos llevará el descubrimiento de las llamadas células madres, cómo será la familia del futuro, etc., etc.

Mi experiencia en el mundo de los científicos es que nunca como ahora han sentido que hay algo más allá a donde no pueden llegar con sus conocimientos y reclaman una fe que con seriedad les ayude a vislumbrar el misterio del mundo que a medida se acerca más es más inalcanzable . Tal vez una de las formas de mayor ausencia eclesial sea la de las ciencias humanas, porque hemos creído que, encerrados en nuestro seguro fanal de doctrinas, todo lo teníamos resuelto. Lo peor de todo es que no nos dejamos preguntar y pasamos la vida en defender y defender.

Lo mismo que decimos de las ciencias podemos decir de otras realidades donde la inculturación viene a ser un proceso que se realiza en el diálogo y donde el agente principal tiene que ser el receptor del mensaje y nunca el mensajero. La fuerza creadora de Dios está desde mucho antes que apareciera en forma histórica encarnada el Verbo y se remonta a la primera Creación, que fue el origen de la Vida, antes del cielo y la tierra.

La palabra, pues, no es ni de teólogos, ni filósofos, sino de científicos. Los grandes paradigmas de este siglo han venido marcados por los cambios profundos que se han producido en Occidente desde las viejas concepciones mecanicistas hasta la teoría cuántica de Max Planck o la teoría de la relatividad y de la materia en energía o a la inversa de Einstein. Pasos de esta naturaleza han rebasado cualquier creación académica y, las ciencias del pensamiento han tenido que someterse a los dictámenes irrebatibles de las ciencias físicas y matemáticas. Nuestras viejas concepciones de espacio, tiempo y materia no eran sino quimeras. El mundo objetivo no parece existir fuera de la conciencia, que determina sus propiedades. Así, el universo que nos rodea se vuelve cada vez menos material. "No es ya comparable a una inmensa máquina, sino más bien a un vasto pensamiento", como dice Jean Guitton (Guitton: 12).

Tenemos que aceptar que la realidad en sí no existe: depende solamente del modo que aceptemos observarla. Las entidades elementales 
que la componen pueden ser, al mismo tiempo una cosa (una onda) y otra (una partícula), y en cualquier caso su realidad es indeterminada. Llegar al límite de esta oscilación, la frontera de lo divisible, significa acercarnos a la realidad de un Ser trascendente, que a la vez es causa y sentido del universo y que nos lleva al meta-realismo, donde acaba la frontera del fraccionamiento de la materia posible y nos sitúa frente a un límite espiritual más cerca de Dios. Las leyes de la relatividad y de la materia y energía han dado cauce a un nuevo orden. Es posible establecer una alianza entre saberes físicos y conocimientos teológicos (GS, 5, 15, etc.).

Pero a los avances en las ciencias físicas, que han superado el mecanicismo cartesiano, debemos agregar los que se han venido realizando en el orden de la biología y la genética que, como dije al comienzo, revolucionan nuestra percepción de la realidad de la Creación (GS 33, 34, 36). Detrás de todo ello y, simultáneamente a la teoría de Edgar Morin sobre la Naturaleza, latía la vuelta a la unidad, no desde la homogeneidad, sino a partir de la complejidad y a la inversa. Es decir, comenzábamos a entender que todo era diferente a todo pero que nada podía asumirse fuera de la inconmensurable complejidad, en su atomizada asociación de elementos que convergían en una macrounidad.

Entre 1822 y 1884, un monje agustino, Abad en Brno, antiguo imperio austro-húngaro, hoy dentro de la República Checa, seguidor de la teoría de la evolución, había descubierto las leyes de la herencia entre los años 1856-1863 con el cruce genético de guisantes. El ensayo fue leído en la Sociedad de Brno para el Estudio de las Ciencias Naturales y, aunque al principio no asombró, sí produjo rápidamente una consternación científica. Desde allí se enviaron copias a 120 centros de Europa. Más tarde De Vries, Correns y Tschermack, redescubriendo en 1900 el trabajo de Gregorio Méndel, lo declararían fundador de la genética. La metodología del trabajo es un modelo de investigación y precisión, más en un tiempo donde conceptos como fenotipo y genotipo, caracteres dominantes y recesivos, locus, cromosomas, ácidos nucléicos eran desconocidos por Darwin y Méndel.

Aún más. Al comenzar la década de los treinta, estaban ya definidas las bases del pensamiento sistémico. A él se había llegado por distintos caminos: la biología organicista, la sicología de la Gestalt, la ecología, la física cuántica y la física nuclear. Más tarde el descubrimiento el ADN y del ARN, base del código genético, han dado una fundamentación a esta teoría que se ha convertido en piedra angular del pensamiento filosófico distante al esencialismo y la abstracción especulativa. 
El pensamiento sistémico además sostiene que las partes no tienen sentido por sí solas, sino que forman conjuntos, sin los que carecen de sentido. Entrañan una nueva mirada a la ciencia como camino para descubrir las infinitas potencialidades de la Creación. De hecho en la década de los setenta surgieron dos novedades en la investigación: la matemática de la complejidad y la autoorganización, dentro de las cuales está el concepto de patrón, que es algo más que átomos y moléculas, algo material e irreductible. En el caso del cerebro las formas como se asocian los cromosomas, los genes, las moléculas desplazan cualquier febril imaginación.

Humberto Maturana demostró que la estructura de los seres vivos es la manifestación física de su organización. Se trata de una red de procesos de producción, en que la función de cada componente es participar en la producción o transformación de otros componentes. De este modo la red se hace a sí misma continuamente. Es producida por sus componentes y, a su vez, los produce. Es un sistema vivo, el producto de su operación es su propia organización (Maturana: 23 ss.; Capra: 112). Se trata de la teoría de la autopoiesis, que viene de auto, propio, y poiesis, creación.

Damasio y Llinás, estudiosos de la neurología han demostrado que las emociones y el yo son la consecuencia de una serie de interrelaciones que separan los conceptos de cerebro, mente y consciencia. La sicología de la Gestalt, contemporánea a ellos, se caracteriza por afirmar que el todo es más que la suma de las partes.

\section{CREACIÓN, CRISTO CÓSMICO Y LA VIDA}

Un caleidoscopio deslumbrante, un destello inefable, un esplendor de alborada, donde cada cosa tiene su color irrepetible y es, al mismo tiempo, un mosaico gigantesco que se asocia a la unidad de un conjunto cósmico de proporciones misteriosas. Mirando atentamente a la realidad que nos circunda comprendemos la complejidad de las interrelaciones y redes de sus partes e integramos la unidad que da sentido a cada cosa y que la evolución, que continúa inagotablemente, va haciendo transformarse en cada momento del río de la vida.

Todo tiene un origen y un destino común; desde la microscópica bacteria hasta las estructuras más complejas, mantiene el equilibrio en una permanente adaptación a las tensiones internas que se generan (Capra: 129, 136; Störig: 780). Y la ciencia va evidenciando con toda luminosidad la infinita cantidad de posibilidades que existen en la Creación. Hay que profundizar en el origen biofísico de la Vida y acompañar desde el inte- 
rior de la ciencia los procesos de inculturación y de cambio profundo que se producen en el mundo (Duve: 1999; Soberón: 12).

El ser humano no es distinto al cosmos: es su plenitud y conciencia. Nuestro corazón, con sus desbordantes pasiones y miserias más profundas, es una consecuencia de estas sensibilidades desarrolladas, de la vida universal que todo lo invade.

El espacio, el paisaje, la inmensidad del cielo estrellado en el silencio de la noche, la esplendorosa diversidad de vida que nos circunda, el sol, el agua, las plantas y los animales, no son escenarios inertes y pasivos, neutrales ante el drama del hombre, ajenos a sus luchas y desvelos. Son parte solidaria del tiempo, de nuestro tiempo, de nuestros sueños y utopías. No cantamos al entorno porque sea solamente bello. Todo forma parte de nuestro ser desde el principio unitario de la explosión primera. Desde la Creación de la Esencia Viviente (Boff,58-3).

Ilia Prigogine ha mostrado cómo las estructuras disipativas, es decir, los sistemas abiertos, cuestionan el sentido clásico del tiempo lineal. El tiempo no es un mero parámetro del movimiento interno de un mundo en permanente transformación y transfiguración; es el paso de niveles de desequilibrio a niveles más altos de equilibrio interior. A partir de aquí la Naturaleza, incluyendo al hombre, se presenta como un proceso de autotranscendencia, que va más allá de la historia (transhistórico) y de lo físico (transfísico). Se da en ella un principio de cosmogénesis mediante el cual, en la medida que los seres aumentan su complejidad, van abriéndose, superando la entropía de los sistemas cerrados. La fuerza de todas las religiones está precisamente en su intencionalidad hacia lo transcendente absoluto, que tiende a "una tierra sin mal", fusión de tiempo y eternidad que sea la realización suprema de la armonía de la vida, del hombre con el cosmos. Es así como cobra sentido pleno aquella máxima evangélica del Sermón del Monte: "Felices los mansos, porque recibirán la tierra en herencia" (Mt 5,5).

Nos percatamos así asombrados lo que ha significado a lo largo de la historia el dualismo maniqueo: espíritu y materia, alma y cuerpo, tierra y cielo, buenos y malos, cielo e infierno, civilización-barbarie, paganos y cristianos, izquierdas y derechas, Este y Oeste, Norte-Sur, hombre-mujer. No se trata de dos historias paralelas, sino de una sola, un solo tiempo interior y profundo, una sola vida.

En nombre de esta espiritualidad dualista ha emergido en el mundo el fundamentalismo de la verdad abstracta, origen de los autoritarismos, intolerancias y violencias a lo largo de la historia. La condensación de este 
espíritu en conceptos contrapuestos como civilización barbarie, de raíz grecorromana, cristiana y hegeliana (Leopoldo Zea. Discurso desde la marginación y la barbarie. México: FCE, 1990) impidió que percibiéramos el mundo americano y amazónico (es decir, sus civilizaciones, su espacio, su geografía, su cosmovisión) como diferencia. Eran simple y llanamente sociedades atrasadas, espacios salvajes, que era necesario domesticar. El "geist" del tiempo lineal marca el rumbo de la historia, y solamente embarcándose en él será posible el progreso hacia adelante que hoy, arrogantes, hemos denominado desarrollo. La holística tiene una dimensión subjetiva y espiritual que nos lleva a entender lo otro desde lo otro mismo, y al otro desde la percepción de ser distinto.

Si miramos al otro y su mundo como inferior, terminaremos convirtiéndolo en objeto justificatorio de nuestra acción civilizadora o evangelizadora, reproducimos la actitud de cualquier colonizador (Mc 9,38-41). He aquí uno de los posibles sentidos de "misión", sea religiosa, educativa o tecnológica. Cuando vemos el espacio viviente como objeto de ocupación o invasión; cuando pretendemos avasallarlo y manipularlo como objeto que satisface nuestras ansiedades espirituales, estamos destruyéndonos y nos hacemos víctimas de nuestro pecado. No se trata de respetar al otro y a lo otro por sí mismo, sino de satisfacer mis instintos egoístas como un organismo viviente único que aspira a la plenitud aprovechándome con cálculo perverso de los demás. El universo entero está en mí, en todos sus elementos, incluso los aparentemente más burdos e inertes. ¿Cómo podemos destruirnos, agazapados en el tumulto de la sociedad global, sin ser capaces de conocer la influencia de las estrellas y los astros en la conformación de la biosfera, en el oxígeno que llena nuestros pulmones, en la luz, en la humedad, en el régimen de los ciclos de las lluvias? Nos pertenecemos mutuamente, nos debemos, somos el mismo organismo. Solamente la solidaridad cósmica, en nuestro caso el ecumenismo universal, salvará el Planeta. Sólo el amor, versión cristiana de la visión holística, llevará el universo a su plenitud escatológica.

\section{5. ¿Y DIOS, NUESTRO DIOS?}

Las relaciones, armónicas o tormentosas, con nuestro espacio, van dejando marcas profundas en nuestro inconsciente, y son como huellas que laten profundamente en la memoria, donde se van acumulando experiencias irreversibles e irrepetibles al paso siempre rejuvenecido del tiempo. Una espiritualidad cósmica mantiene también su arqueología interior, los arquetipos del inconsciente colectivo que van quedando sedimenta- 
dos, mucho más allá de nuestras sensaciones conscientes. Jung planteó que lo más profundo que existe en el inconsciente es el arquetipo de lo Absoluto. A saber: el Espíritu, lo Absoluto, todo lo llena y penetra, le da consistencia óntica. Formamos parte de una unidad orgánica indivisible.

Cuando un periodista le preguntó al Obispo Casaldáliga, a qué se refería cuando hablaba tanto de "cambiar de Dios", contestó: "A eso. A ensanchar la propia teología, la propia fe, a dejarle a Dios "ser Dios", a ir creyendo siempre más en el "Dios mayor", a reconocerlo a través de las múltiples presencias de su Presencia, única, universal y salvadora. Yo me pregunto en un poemilla: Mi Dios, ¿me deja ver a Dios?... Tenemos que hablar de una teología planetaria. No se trata de negar la revelación bíblica... Se trata de rever nuestra teología miope y colonizadora. Se trata de creer efectivamente en la voluntad salvífica universal de Dios que envío a su Hijo al mundo no para condenarlo sino para salvarlo" (La Paloma de Ayacucho. Entrevista. Sao Félix do Araguaia. Mimeo.).

Tomamos como punto de partida algunos elementos para una espiritualidad macro-ecuménica:

\section{A. Complejidad, identidad y complementariedad}

¿Cómo tendremos que vivir desde una profunda actitud religiosa el cambio de nuestra visión universal? La ecología como tal es un corsé que nos ahoga, nos limita y nos cierra el horizonte si no la entendemos más allá del conservacionismo o de su dimensión social. Tiene que estar ensamblada en el ámbito de una espiritualidad macroecuménica que comprenda la totalidad del universo. Sus rasgos mayores podrían ser, a grandes trazos, los siguientes:

1. La madurez y la libertad en la afirmación de la identidad propia desde el género, la cultura, la fe religiosa y la condición social.

2. La escucha contemplativa del Dios de la Vida que sigue revelándose a través de una Creación efervescente y dinámica, y la pasión por su proyecto de plenitud, equidad y justicia.

3. La apertura fraterno-sororal a todas las personas desde sus propias culturas y religiones, y el diálogo sincero, crítico y autocrítico, en pie de igualdad. Solamente se ama lo que se considera igual a uno mismo.

4. La sensibilidad misericordiosa y la solidaridad eficaz frente a toda situación de marginación y muerte. 
5. La celebración, gratuita y esperanzada del Dios de la Vida, de la Vida de la Humanidad y de la Vida de la tierra y el cosmos, hoy dramáticamente amenazada.

Desde esta visión holística y abierta del mundo, entendemos lo que significa el ecumenismo, la mirada a los otros, a otras religiones y al cosmos viviente, cuyo tiempo florece a cada instante. Es el retorno de la diversidad y la complejidad a la unidad en la comunión.

\section{B. Los gritos de las criaturas, evidencias de Dios}

"Dios calla, pero hablan sus obras" (San Agustín, Sermón 313). Nuestra experiencia interior nos lleva a mirar con asombro a las criaturas y a ver en ellas, como en nosotros, el reflejo y las huellas del paso de la Divinidad. La Creación es una explosiva teofanía en permanente crecimiento, un gigantesco espectáculo de luz y sonido, que nos deslumbra, que nos llama. Pero el espectáculo mayor, que nos lleva a sentirnos una parte insignificante del universo creado, tiene que desarrollarse y transformarse de lo exterior a lo interior, y desde el alma a Dios. "No vayas fuera. En tu interior mora la verdad. Y, si te encuentras que eres mutable y pasajero, transciéndete también" (San Agustín, De Vera Religione, 39, 72). No se trata de una admiración meramente estética de lo que está fuera de nosotros, sino de un camino que nos lleva a transcendernos desde fuera hacia el secreto del alma, incluyendo la infinita diversidad y complejidad en que estamos envueltos.

\section{Nuestra respuesta, la libertad en el amor}

De esta mirada al mundo y a la Vida que lo inunda en estado de gracia fluye una actitud de profundo equilibrio interior, de una paz inagotable, cuyas características o rasgos podríamos resumir así:

1. El sentimiento de profunda libertad en un amor que incluye sin excepción a cada hombre, a cada ser creado, a cada mínima cosa que forma parte viviente del universo. La madurez va sucediendo en nuestras vidas en la medida que salimos de nosotros mismos y nos abrimos a los demás. Ser libres es el fruto primero de esta fusión. Todo es bueno, el mal es simplemente la ausencia de bien.

2. Una profunda y respetuosa sensibilidad, que no oculta su compasión y misericordia con la tierra que sufre, con el hombre pobre que padece o delinque, el que reniega de la vida y el que 
canta vibrante de esperanza a la luz y la energía que todo lo llena.

3. La confianza en todo y en todos, el optimismo ilimitado en el destino final de la tierra y de los hombres; la conciencia asertiva y confiada en que somos parte de un universo que crece, a veces muy a nuestro pesar, por la energía viviente implantada desde la creación. La tristeza del pesimista entristece al cosmos. Nuestra alegría lo rejuvenece, lo hace sonreir.

4. Capacidad de escucha paciente y contemplativa que provoque en nosotros un sentimiento de gratuidad, de desprendimiento, de hacer prevalecer en nosotros los valores del ser y de la vida sobre los del tener, del poseer y de la muerte. Vivir el apacible tiempo circular, donde todo vuelve, e ir desprendiéndonos de la angustia de la linealidad de la historia.

Pero hay algo más: la referencia permanente a la Creación, y la visión de la Redención en esta perspectiva, nos harán más inclusivos, más abiertos y acogedores ante las diferencias de pensamiento y de cultura que se han convertido en barreras infranqueables y en origen de la violencia, al contrario de lo que sucedió con Pablo de Tarso en el Areópago de Atenas (Act. 17, 16 ss). Está por descubrir cuál es el camino que se ha de seguir para que no nos distanciemos más de la historia y de la realidad y nos incluyamos en la marcha de la humanidad. Debemos pasar de la realidad de las fórmulas de la tradición repetidas. Boff ha dicho con acierto: "Es importante pasar nuestro Rubicón que nos mantiene en la prehistoria de nosotros mismos para irrumpir en la tierra prometida de los seres humanos entrelazados en una red de vida, de sentido de colaboración, de diferencias complementadas, construyendo juntos el reino humano en el cual la flecha de la creación rumbo a una unidad orgánica y supremamente bienaventurada que nosotros llamamos Dios" (Boff: 92).

Algo más cierto aún: la valoración del universo indígena nos ayudó a abrir los ojos para comprender que el problema del anuncio de la fe es, ante todo, un asunto de inculturación y que, mientras la cultura no esté dignificada por el reconocimiento a plenitud de la persona, será inútil todo el trabajo que podamos hacer para santificar al mundo. Un mundo que ha sido ya santificado cuando salió de las manos del Dios Creador desde el Misterio Trinitario (GS, 90).

"La salvación última no vendrá por manos humanas, ni siquiera cristianas. La visión escatológica de la salvación de los cristianos no puede 
realizarse en la historia. Por esta razón los cristianos no debemos identificar ningún proyecto con la plenitud del Reino de Dios" (Bosch: 488).

\section{6. ¿QUÉ COSA EXISTE SINO PORQUE TÚ ERES? (San Agustín, conf. 11,5)}

Dios no es la criatura, ni la criatura es Dios. Uno y otra son diversos. Todo no es Dios, pero Dios, la Vida de la Vida está en todo. Este panenteísmo, contrario al panteísmo, es una actitud donde asumimos que la divinidad es la realidad en su sentido más totalizante, pero que la creación es fruto de su gratuidad desbordante. La nueva alianza encuentra sus raíces en el abismo de la mente humana. Ella como expresión y conciencia del cosmos es el punto de partida para recuperar el eslabón perdido en la cadena de los seres. Esta cadena está anclada en lo sagrado, en Dios, principio de la autoorganización del universo. Aquí encuentra la tierra los argumentos de su dignidad. Cuando Pablo llega al Areópago de Atenas y comprueba que han dedicado monumentos a cada una de sus divinidades, halla una lápida dedicada "Al Dios Desconocido". Y les dice: "Hombres de Atenas, veo que son ustedes hombres sumamente religiosos. Porque, al recorrer la ciudad y contemplar sus monumentos sagrados he encontrado también un altar en el que está grabada esta inscripción: "Al Dios desconocido". Ahora bien, lo que adoran sin conocer, vengo a anunciárselo. El Dios que hizo el mundo y todo lo que hay en El, siendo Señor del cielo y de la tierra, no vive en santuarios fabricados por hombres. Y su culto tampoco requiere objetos salidos de la mano del hombre, como si él necesitara algo. Pues él da a todos la vida, el aliento y todo lo demás. De una misma sangre hizo toda la raza humana, para establecerla sobre toda la faz de la tierra, y determinó el tiempo y los límites del lugar donde cada pueblo había de habitar... En realidad Dios no está lejos de cada uno de nosotros, pues en él vivimos, nos movemos y existimos, como algunos de sus poetas dijeron: "Somos de la raza del mismo Dios" (He 17, 16-28).

\section{CÓMO HEMOS DE HACER PARA QUE NUESTRA ACCION SEA MISIONERA EN EL PARADIGMA DE LA CREACIÓN}

Hasta ahora la Creación se había visto relegada a su sentido original y no había asumido el carácter de una Creación continua ni la nueva Creación escatológica perfeccionada de todas las cosas. Moltman, para presentar un concepto integral de la Creación habla de un proceso unitario donde entran la Creación original que continúa en la historia de la Creación 
y se consuma en la nueva Creación de todas las cosas (Moltman: 1987, 199 ss). Se especifican más puntualmente en la Creación de Dios por el Espíritu y la Palabra; la consolidación y evolución de la Creación, como creatio continua; la renovación de la Creación donde Dios es el anticipo de la nueva Creación, donde "renueva la faz de la tierra" (Sal 104, 30; GS 39 ss).

\section{A. Missio Dei in Creatione}

Las formas de mantenimiento del sentido de una misión como implantación de la Iglesia tienen que ser replanteadas desde un la apertura a la Creación donde los hombres son la inteligencia del universo, sobre todo los marginados y excluidos, criaturas gratuitas de sus manos y de su corazón. Volver a la Creación significa regresar a raíz del hecho creador que incluye la realidad unitaria completa en todas sus dimensiones y componentes, incluyendo la ecológica, racial, de género y otras. En esta clave debe leerse el texto de Mt 25,31 ss. Lo cual lleva consigo:

a. Participar activamente en los procesos de interculturalidad entre los pueblos de distinto origen, raza, religión y tradición, teniendo en cuenta las oleadas migratorias del Sur al Norte. No habrá en el mundo la tendencia hacia la construcción de un modelo de paz y de justicia, mientras no haya una actitud eclesial de conjunto que trate de modo dialogante las diferencias (AG 3,5 ss; GS 78).

b. Comprender las relaciones Norte-Sur, desde el mundo de los empobrecidos y excluidos, por una transformación de las estructuras políticas, sociales y económicas para que su calidad de vida se transforme. En los últimos tiempos hemos sido testigos de situaciones de franco imperialismo que merecen una sólida acción profética (AG 3,5 ss; GS, 78; Capra: 25; Boff:81-92).

c. Misión en transformación que quiere decir desempeñar una actividad transformadora de la realidad, pero que signifique una necesidad de que la misión vaya siendo transformada. Los proyectos del Nuevo Testamento tenían el propósito de definir la Iglesia en su tiempo. Hoy tenemos la misión de realizar lo mismo creativamente, haciendo una lectura adecuada de los signos de los tiempos, alentada por el Espíritu de Dios.

d. Los procesos migratorios entre los distintos bloques y países contienen un clamor humano y, por lo tanto divino, y nos actua- 
lizan hoy el espíritu de los pasajes del AT donde se acoge al extranjero, al huérfano y a la viuda. Constituyen el punto de partida para la creación de un nuevo orden internacional entre bloques y pueblos. Todo esfuerzo que se haga para romper nuestras fronteras nacionales y eclesiales es poco. Los nacionalismos, los sectarismos son el mayor peligro para el ejercicio de la fe en el amor.

e. El sometimiento de los países del Sur a los pueblos del Norte requiere que se descubran dimensiones nuevas del Evangelio de Jesús que llamó a los desposeídos, a los marginados, a los oprimidos y a los leprosos, que estuvo siempre de parte de quienes no habían sido reconocidos por la sociedad (Mt 5, 3-12; 11, 3-5; Lc 4,18-19). La opción preferencial por los pobres como lo plantea Puebla incluye otras dimensiones de la vida, como el racismo, la diferencia de género, la apertura al diálogo cultural. La teología negra viene a ser una aplicación contextuada de la opción preferencial por los pobres. En la tradición de la teología occidental el tema de los pobres ha sido un asunto de ética social y no propiamente de teología o de epistemología cristiana. Aquí la teología y la ética van juntas (Bosch: 531-534). La identificación del Señor con los que sufren nos lleva a considerar a los pobres como un asunto del Evangelio.

f. Unir a todos los hombres bajo una autoridad única e igual en el mundo que supere las contiendas y conflictos que las Naciones Unidas no han sido capaces de superar (GS 82, 83, 84, 88; Populorum Progressio, 39).

\section{B. Diálogo interreligioso y misión}

a. Debe caracterizarse por una tensión creativa que supere la pretensión absolutista. Tal vez sea un ámbito donde la teoría debe ser superada por la práctica. Hay que aceptar en primer lugar el hecho real de la existencia de otras religiones y acceder a ello abiertos y esperanzados. No hay posibilidad si accedemos a disgusto. Tenemos que convivir con gente de las más variadas religiones. Otros factores han de ser: el compromiso; la confianza en el Espíritu creador que hace no nos sintamos poseedores de toda la verdad, sino sus buscadores; la humildad, por la acción de la gracia recibida gratuitamente. El riesgo, la ambigüedad corre a través de todas las sociedades humanas, todas las religiones, aun 
del cristianismo. Todos somos vulnerables. No es posible acercarnos a otros seguros de qué llevamos, sin necesitar y acoger lo que nos den. El diálogo solamente es posible en humildad, cuando sufrimos la contradicción y nos abate la incertidumbre.

b. En el pluralismo, donde las pretensiones rivales de la verdad del mosaico ya no existan, donde no cabe ortodoxia, donde todos somos herejes en el sentido original de la palabra (Bosch: $588 \mathrm{ss}$ ).

c. La interpretación de la salvación depende de la distinta teología de la salvación en que se funde. Para Lucas la salvación es, sobre todo, algo que se realiza en esta vida ( $\operatorname{Lc} 4,21 ; 19,9 ; 23,43)$. Pablo subraya la naturaleza incipiente de la salvación, que se inicia en este mundo. El Espíritu Santo es sólo las primicias de los dones de Dios a favor de los hombres ( Ro 8, 23). Somos salvos en la esperanza. En el período patrístico griego la expectativa escatológica menguó y tomó el perfil de paideia, de una elevación paulatina del creyente hasta lograr un rango divino, theosis. Cada salvación consistía en la redención de las almas individuales en el más allá. Aunque se prestase servicios evangélicos al cuidado de los enfermos, los huérfanos, a la educación, a la multiplicación de obras para el desarrollo, su propósito final consistía en predisponer a las personas de modo favorable a Cristo. La crítica moderna a la religión se encuentra precisamente en que ésta significa una dependencia total de Dios y, como salvación eterna, en el más allá. Y es como el desarrollo de un remanente de la etapa infantil de la humanidad. Hoy entendemos (GS 1) que la salvación debe ser integral y que comprendiendo la dimensión temporal debe abarcar también la dimensión escatológica.

\section{Dimensión contemplativa}

a. Si en todo está la mano de Dios, si El es la causa de todos, una primera actitud que se impone es la contemplación de lo que El está haciendo y del mensaje que a través de lo que hace llega para nuestra conversión y enriquecimiento, al modo como supone la teología india desde la cual también se salva de su estancamiento la espiritualidad tradicional de la Iglesia.

b. La misión como búsqueda de la justicia, superando los extremismos de una y otra parte, pero teniendo como objetivo principal el ecumenismo desde la Creación, desde el pluralismo donde 
cada quien asume su papel en modo dialogante, contemplativo y desprejuiciado.

c. Hay que superar la convicción de que el único Dios verdadero es el nuestro y los demás carecen de él. Niega la verdad de los demás, instalando en el mundo la discordia. El diálogo yo-tú divino nos lleva a descubrirle en las demás historias, que son historias tan salvíficas como la nuestra, que tienen verdaderas inspiraciones contemplativas y místicas, en un modelo de espiritualidad planetaria y ecológica.

\section{CONCLUSIONES}

Soy consciente de las limitaciones de toda índole en un trabajo de esta naturaleza. Estoy sin embargo profundamente convencido de que el camino de la Creación es donde gentes de todos los pueblos, culturas, religiones, incluyendo a los agnósticos (que en el fondo significan una crítica a la fe desde la cultura de la posmodernidad), nos podremos encontrar en una aurora boreal de paz y respeto. Se afecta a toda una cultura cuando se pretende transformar una religión sin tener en cuenta todos los demás elementos culturales que la conforman. Concluirá mi exposición con algunas pinceladas de síntesis de lo que he pretendido ofrecer en este Magno Congreso del COMLA 7-CAM 2.

1. El paradigma misionero, las iglesias cristianas, el modo de entender la salvación, están en crisis profunda. Hemos de lanzarnos en la búsqueda de nuevas rutas creativas en el camino de la fe.

2. El descubrimiento de la infinita complejidad de la Creación nos aproxima a la verdad de Dios y contribuye a que se vaya aproximando la nueva Creación que gime con dolores de parto (Rom $8,22-23)$. La subestima en el imaginario del pueblo fiel de los avances de la ciencia ha hecho que nos hayamos visto relegados como infantes en nuestras creencias y no tengamos acceso pleno iure a la pos-modernidad en una visión y experiencia de fe. Cualquier descubrimiento de la ciencia es una revelación, una epifanía de Dios. Los avances de los científicos han de ser considerados como aportes cocreadores con Dios. Si la verdad nos hace libres, ¿qué podemos temer por un futuro que está en manos del Espíritu Santo? La apertura al Dios de la Vida nos librará de nuestras intransigencias frente a situaciones que no 
está a nuestro alcance cambiar y además cuyo destino final es inexorable.

3. Mirar a la Creación abre un espacio amplio y generoso, que desarrolla un ecumenismo tolerante y abierto en forma horizontal y dialogante, aun cuando, fuera de prejuicios, cada forma de expresión de cultura y religión mantenga su propia identidad y los elementos que la hacen diversa.

4. Es posible abrir espacios al sentido de la misión eclesial que nos aproximen al mundo de lo real, concreto y físico, nacido de la mano del Dios de la Vida de quien procedemos y al que nos dirigimos, fuera de todo sectarismo y proselitismo al creer que somos los únicos poseedores de la verdad y nos pongamos distantes de la vida. Lo que caracteriza a una comunidad de creyentes que peregrina por el mundo es que se sienta solidaria con las angustias y pesadumbres de los hijos de la tierra (GS,1). Los cambios de la historia deben significar también transformaciones profundas de los puntos de vista de la teología cristiana. La historia de cada pueblo es una historia salvífica. En ella debemos encontrar, bajo la luz de la tradición y de la historia eclesial, manifestaciones vivas de Dios, experiencias que nos den aliento y ayuden a emprender con empuje apostólico un modelo que recoja las aspiraciones de los pueblos y contribuyan a la construcción del Reino.

5. Siendo así que la Creación, con todos sus logros y avances en la construcción de su vida en el tiempo son una parte importante y necesaria, no significan sin embargo el Cristo total que aparecerá al fin de los tiempos y tiene dimensiones escatológicas más allá de cualquier avance de la humanidad. 


\section{OBRAS CONSULTADAS:}

Aguilar Sahagún, Guillermo, Cruz Jiménez, S. y Flores Valdés, J. Una ojeada a la materia. (1997). México: Fondo de Cultura Económica. ATIENZA, Juan G. Los pecados de la Iglesia: memoria de una ambición. 2000. Barcelona: Juan G. Atienza/ Martínez Roca.

BetTo, Fray. A obra do artista. Uma visao holística do Universo. (1995). Sao Paulo: Atica.

BLÁZQUEZ, Niceto. Bioética: La nueva ciencia de la vida. (2000). Madrid: Biblioteca de Autores Cristianos.

Boff, Leonardo. Ecologia: Grito da terra, grito dos pobres. (1995). Sao Paulo: Atica.

BofF, Leonardo. La voz del arco iris (2003). Madrid: Trotta

Bosch, David J. Misión en transformación: cambios de paradigma en la teología de la misión. 2000. Grand Rapids (EE.UU.): Libros Desafío.

CAPRA, Fritjof. La trama de la vida: Una nueva perspectiva de los sistemas vivos. (1999). Barcelona: Anagrama.

ClARO, Francisco. A la sombra del asombro: El mundo visto por la física. (1999). Santiago de Chile: Andrés Bello.

Concilio Vaticano II. Constituciones. Decretos. Declaraciones.(1966,2a). Madrid: Biblioteca de Autores Cristianos (BAC)

GARCíA, Joaquín. Conferencias (pro-manuscripto). (2001). Santiago de Chile.

DAMASIO, Antonio R. El error de Descartes: La razón de las emociones. (1996). Santiago de Chile: Andrés Bello.

DAMASIO, Antonio. Sentir lo que sucede. Cuerpo y emoción en la fábrica de la consciencia. (2000). Santiago de Chile: Andrés Bello.

DiCCIONARIO DE CIENCIAS. 2000. Madrid: Complutense.

DuPUIS, Jacques. Hacia una teología cristiana del pluralismo religioso. 2000. Santander: Sal Terrae.

Duve, Christian de. Polvo vital: El origen y evolución de la vida en la tierra. (1999). Santafé de Bogotá: Norma.

GirARDI, Giulio, DAMBoreneA, Juan J. de y otros (1994). Cristianismo, justicia y ecología. Madrid: Nueva Utopía.

GiUsTI, Miguel. Alas y raíces: Ensayos sobre ética y modernidad. Lima: Fondo Editorial de la Pontificia Universidad Católica del Perú.

GonZÁlez FAus, José Ignacio. La autoridad de la verdad. Momentos oscuros del magisterio eclesiástico. (1996). Barcelona: Herder 
GuITTON, Jean; Grichka e Igor Bogdanov. Dios y la ciencia. Hacia el metarealismo.(1998). Cuarta Edición. Madrid: Debate.

HoBSBAwM, Eric. Historia del siglo xx: 1914-1991. (1998). Barcelona: Grijalbo Mondadori.

HuXley, Aldous. Un mundo feliz. (1999). Barcelona: Plaza \& Janes.

IIAP. Visión del desarrollo de la Amazonía peruana al 2022. 2 edic.(1997) Iquitos: IIAP.

KAlliola, R. y FloRES, Salvador. Geoecología y desarrollo amazónico.(1998). Turku: Turun Yliopisto.

Kalliola y otros. Amazonía Peruana: vegetación húmeda tropical en el llano subandino.(1993). Finlandia: Paut/Onern.

LACADENA, Juan Ramón y otros. En el centenario de Mendel: La genética ayer y hoy (1984). Madrid: Alambra.

LLINÁs, Rodolfo R. El cerebro y el mito del yo. (1993). Bogotá: Norma.

Lydon, Juan J. (Comp.). Ecoteología: una perspectiva desde san Agustín. (1996) México.

Lydon, Juan J. (Comp.). La inculturación: Teoría y práctica desde el carisma agustiniano latinoamericano. (1999). México: OALA.

MaturanA, Humberto y VArela, Francisco. El árbol del Conocimiento (1990). Santiago de Chile: Debate.

MATURANA, Humberto y VARELA, Francisco. De máquinas y seres vivos. (1972-1980). Santiago de Chile: Universitaria.

Moltmann, Jürgen. El Camino de Jesucristo (1993). Salamanca: Sígueme

Moltmann, Jürgen. Dios en la Creación. (1997). Salamanca: Sígueme.

MORIN, Edgar. El método. (1988-1993).Madrid: Cátedra.

NiCOLIS, Gregoire, PRIGOGINE, Ilya. La estructura de lo complejo: En el camino hacia una nueva comprensión de las ciencias. (1994). Madrid: Alianza.

ObisPos DE LA AMAZONIA PERUANA Reflexiones pastorales en torno al medio ambiente de la Amazonía peruana. (1996). Lima: CAAAP.

PAPP, Desiderio. Historia de las ciencias: desde la antigüedad hasta nuestros días. (1996). Santiago de Chile: Andrés Bello.

Prigogine, I. La nascita del tempo. (1991).Milao: Bompiani.

Prigogine, I. \& Stengers. I. Entre o tempo e a eternidade. (1992) Sao Paulo: Compania das Letras.

REEVES, Hubert. Ultimas noticias del cosmos: Hacia el primer segundo. (1995). Santiago de Chile: Andrés Bello.

RiAZA Morales, José María. La iglesia en la historia de la ciencia. (1999). Madrid: Biblioteca de Autores Cristianos. 
RuIZ DE LA PeÑa, Juan L. La pascua de la creación: Escatología. (1996). Madrid: BAC.

Soberon mAINERo, Francisco Xavier. La ingeniería genética y la nueva biotecnología. (1999). México: Fondo de Cultura Económica.

STIGLITZ, Joseph E. El Malestar en la Globalización (2003). Madrid. Punto de Lectura.

Storig, Hans Joachim. Historia universal de la filosofía. (1997). Madrid: Ed. TECNOS.

CHARDIn, Teilhard. Le coeur de la matiere (1976). Paris: Editions du Seuil. TreviJAno EtcheVerRia, Manuel. Fe y ciencia: antropología. (1996). Salamanca: Sígueme.

VARgas LlosA, Mario. La utopía arcaica: José María Arguedas y las ficciones del indigenismo.(1966). México: Fondo de Cultura Económica.

Ventosa Oliveras, Lluis. El mal lladre: teologia des del Quart Món. 2000. Barcelona: Claret.

Wilches-ChauX, Gustavo. La letra con risa entra. (1996). Popayán: Fundación FES, Fondo FEN.

WILMUTT, Iann, Keith CAMPBELl y Colin TUDGE. La segunda creación: de Dolly a la clonación.(2000). Barcelona: Eds. B. 